\title{
A case of complete bilateral ophthalmoplegia due to an intrasellar aneurysm ${ }^{1}$
}

\author{
D. O. HANCOCK \\ From the Department of Neurological Surgery, Frenchay Hospital, Bristol
}

The clinical features of infra-clinoid aneurysms were described in the classical papers by Jefferson (1937, 1938). He makes no reference to total bilateral ophthalmoplegia due to this cause in his exhaustive review of the literature, though three cases of partial bilateral involvement are cited.

Bilateral infra-clinoid aneurysms, which might be expected to produce this syndrome, are extremely rare. Jefferson (1938) records four; I could find only six others (Bozzoli, 1937; Hamby, 1942; Heuer and Dandy, 1916; dei Poli and Zucha, 1940; Logue, 1951), and it is notable that bilateral total ophthalmoplegia occurred in only one of the three cases (Mahoudeau, Daum, George, and Rosier, 1949, cited by Jefferson).

Parry and Rogers published a case (1939) which in all probability was due to a carotico-cavernous fistula. Dandy (1937) reports a similar case with bilateral 'almost' total ophthalmoplegia, which he assumed was due to bilateral carotico-cavernous fistulae (case 5), though he had no anatomical proof that a fistula was present on both sides. Dollfus, Taptas, and Brisac (1947) record an example clinically typical of a carotico-cavernous fistula, where ophthalmoplegia in the other eye followed a normal right carotid angiogram; however, total ophthalmoplegia was not simultaneously present in both eyes.

\section{CASE REPORT}

A previously fit, 59-year-old housewife gave a history of irregular lancinating pain radiating from the right side of the forehead to the temple for three weeks. It was of sudden onset and had persisted. A week later she noticed verittical diplopia on looking to the right. This lasted a further week until the right eyelid closed; the left lid followed suit five days later. There was no facial numbness or tingling.

Examination showed her to be an obese, hypertensive subject (blood pressure $170 / 100 \mathrm{~mm}$. $\mathrm{Hg}$ ), with left ventricular enlargement and pyrexia $\left(100^{\circ} \mathrm{F}\right.$.). She had bilateral conjunctivitis. The chest and abdomen were normal on clinical examination. The findings referable to the central nervous system were impaired visual acuity, J.19 on both sides uncorrected, bilateral complete ptosis

1This paper was read before the Society of British Neurological Surgeons at Derby in November 1961. with widely dilated regular pupils, not reacting to light directly, consensually, or to accommodation. Accurate charting of the visual fields was not possible, and the confrontation test was unreliable; there was no obvious hemianopic field defect, however. The left eye retained very slight downward and outward movement. There was also diminished appreciation of light touch and pin-prick on the right side of the forehead, with bilateral depression of corneal sensation. No other abnormality was present, and there was neither proptosis nor intracranial bruit.

The red and white blood cell counts were normal. The serum cholesterol level was $166 \mathrm{mg} . \%$. The Wassermann reaction was negative.

The cerebrospinal fluid was clear and colourless with normal dynamics. It contained 8 lymphocytes and 46 red blood cells per c.mm. and $57 \mathrm{mg} . \%$ protein.

Conjunctival swabs grew pneumococci and diphtheroids.

The transverse diameter of the heart was increased, and the right half of the diaphragm was raised. Cervical ribs were present on both sides.

The skull showed an enlargement of the sella $(15 \times 15$ $\mathrm{mm}$.) with undercutting of the anterior clinoid processes and erosion of the floor of the sella posteriorly. An arc of calcification was apparent above the sella but no parasellar calcification was visible. The basal view was normal and the superior orbital fissures intact on both sides. The infero-medial aspect of the right orbital foramen was seen to be eroded.

Right carotid angiography showed contrast present in a suprasellar aneurysm only $1 \mathrm{~cm}$. long and directed across the midline; the upper part of the internal carotid artery was displaced upwards and laterally, with considerable narrowing of its lumen. The remainder of the visible vasculature was normal (Fig. 1). The left carotid angiogram was normal and good cross-circulation was demonstrated on right carotid compression.

Three days after angiography the right ptosis was lessening and the downward and outward movement had increased a little in the left eye. The following day a clamp was placed on the right common carotid artery under local anaesthesia. The patient became confused the same evening after the clamp was closed but no weakness of the limbs appeared.

The common carotid artery was ligated and divided $\mathbf{4 8}$ hours later. The blood pressure dropped to $100 / 60 \mathrm{~mm}$. on the patient's return to the ward. She died the following day, having become cyanosed, dyspnoeic, and hypotensive. Cardiac massage was of no avail. 


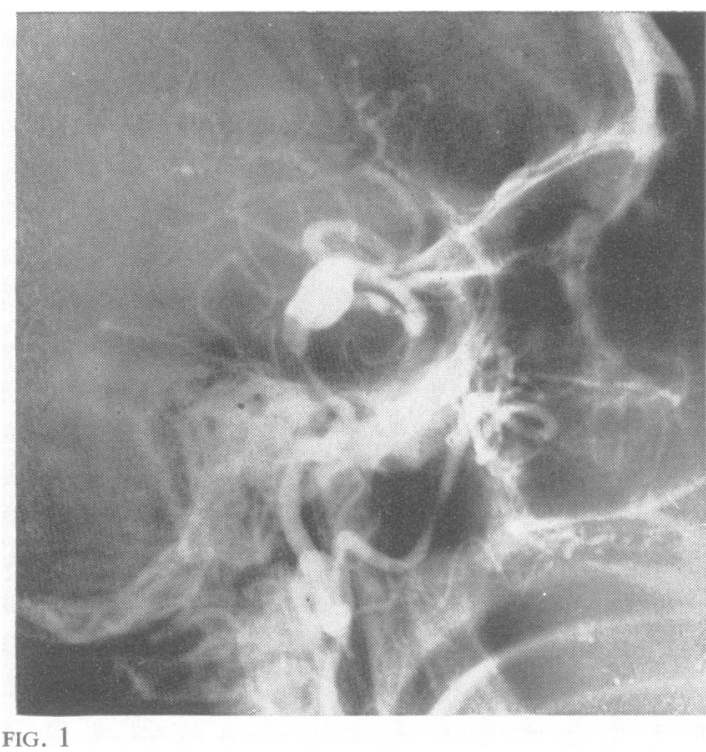

Post-mortem examination (Dr. R. J. Sandry) showed an intrasellar tumour which had slightly indented the floor of the third ventricle. When it was removed from the pituitary fossa the carotid siphon on each side was found to be attached to its lateral aspects, that on the right disappearing into the sac, to reappear on its upper surface (Fig. 2). The walls of the sac were intact. There was also evidence of essential hypertension and cardiac failure. Coronary atheroma was found and the right coronary artery was absent.

Serial sections of the aneurysm after celloidin fixation showed laminated clot but failed to detect the actual site of the fistula.

\section{DISCUSSION}

The remarkable feature of this intrasellar aneurysm derived from one internal carotid artery is the bilateral total ophthalmoplegia it produced. A correct diagnosis was inferred from the erosion of the optic foramen and the angiogram which, coupled with facial sensory impairment, placed the lesion within the cavernous sinus. It is possible that this aneurysm was caused by a congenital mural defect rather than atherosclerosis as the patient had an absent coronary artery and bilateral cervical ribs.

Section of the aneurysm shows a recent haemorrhage which probably determined the presenting syndrome. It seems likely that the sac occupied, and was well accommodated by, both cavernous sinuses for some years. Radiological calcification was visible, and fibrosis was present within the sac at its fundus on the left lateral aspect.

Bilateral ophthalmoplegia is exceptional in cases of infraclinoid aneurysm and is rare even in the very few examples of bilateral aneurysms. Invasive pituit-

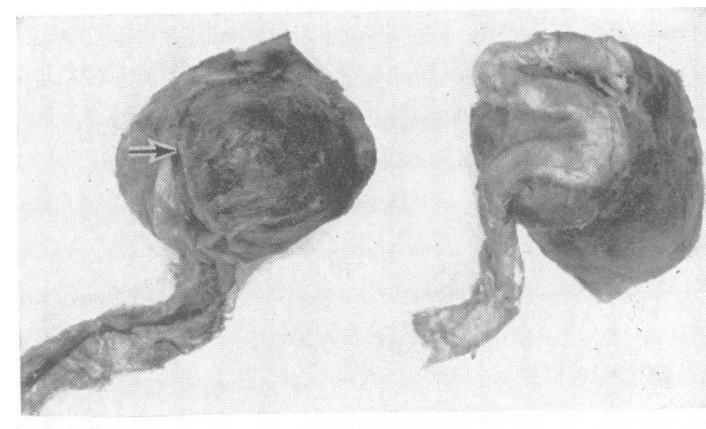

FIG. 2

FIG. 1. Right carotid arteriogram (lateral view). The $\overline{\bar{\omega}}$ posterior bowing and narrowing of the internal carotid $\vec{\curvearrowright}$ artery is clearly visible.

FIG. 2. Right and left lateral aspects of aneurysmal sac; the internal carotid artery can be seen entering its substance (arrow).

ary adenomata do not produce the syndromes (Jefferson, 1940). The cavernous sinus, as its name implies, may accommodate these lesions for some? time before its nervous contents show signs of $\tilde{N}$ damage. The onset of symptoms is sudden, but it mas be a few weeks before the full clinical picture $\$$ evolved. Necropsy may show an aneurysm the age \&fo which must often be greater than the duration of thesymptoms suggests. This implies a long period of silent adaptation until the limit of neurologicalo tolerance is reached. The degree of involvement $8 \mathrm{f}$. trigeminal function is quite haphazard, varying frow none to complete loss (Jefferson, 1953). Involvementi of the motor ocular nerves seems to be invariab though the number affected is not constant. The sixth nerve, as would be expected from its apposition? to the internal carotid artery in the cavernous sinus, is most frequently implicated. Ultimately all com binations of involvement should occur, and this report outlines one of them.

I wish to thank Mr. A. Hulme for permission to publish this case, Dr. G. Thomson for the radiological reports and Dr. R. J. Sandry for the necropsy findings.

\section{REFERENCES}

Bozzoli, A. (1937). Riv. oto-neuro-oftal., 14, 304.

Dandy, W. E. (1937). Zbl. Neurochir., 2, 77.
Dollfus, M. A., Taptas, J., and Brisac (1947). Bull. Soc. Ophtal. Paris p. 458 .

Hamby, W. B. (1942). J. internat. Coll. Surg., 5, 216.

Heuer, G. J., and Dandy, W. E. (1916). Bull. Johns Hopk. Hosp., 27, 311.

Jefferson, G. (1937). Brain, 60, 444

-, (1938). Brit. J. Surg., 26, 267.

, (1940). Proc, roy. Soc. Med., 33, 433.

, (1953). Trans. ophthal. Soc. U.K., 73, 117.

Logue, V. (1951). Brit. J. Surg., 39, 181.

Mahoudeau, D. Daum, S. George, and Rosier. (1949), Bull. Soc. med? Hôp. Paris., 65, 503.

Parry, R., and Rogers, L. (1939). Brit. J. Surg., 27, 179.

Poli, G. dei, and Zucha, J. (1940). Zbl. Neurochim., 5, 209. 